
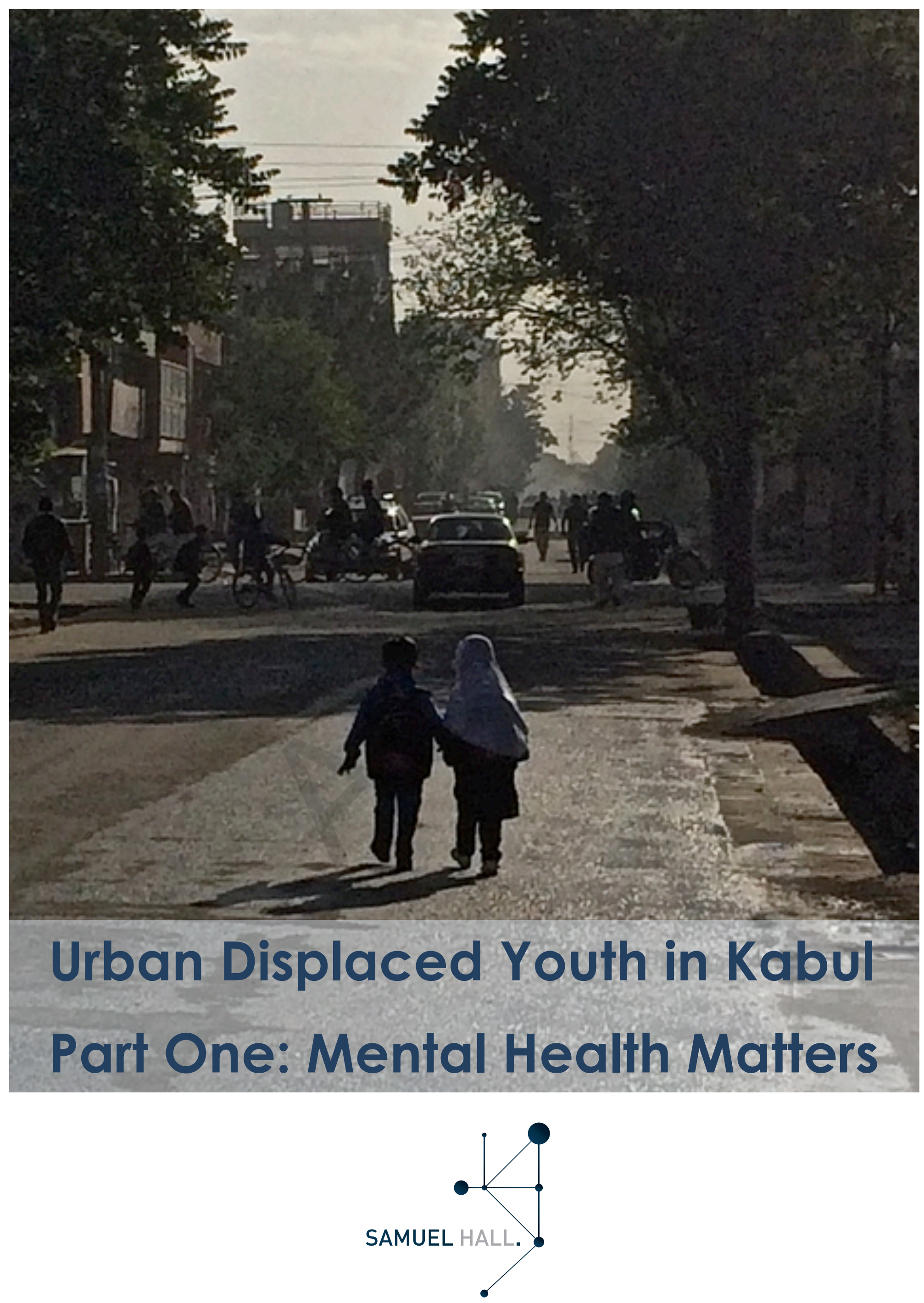
Samuel Hall is an independent think tank with offices in Central Asia (Afghanistan) and East Africa (Kenya, Somalia). We specialise in socio-economic surveys, private and public sector studies, and impact assessments for a range of humanitarian and development actors. With a rigorous approach and the inclusion of academic experts, field practitioners, and a vast network of national researchers, we access complex settings and gather accurate data. We bring innovative insights and practical solutions to addressing the most pressing social, economic, and political issues of our time. To find out more, visit samuelhall.org.

Visit us at www.samuelhall.org

Photo Credits: Naeem Meer

This publication was designed and proposed independently by Samuel Hall based on identified needs on the ground. To ensure a broad-based support and buy-in for a joint action plan, a Technical Working Group (TWG) composed of key agencies was put together at the onset of this research. The TWG is composed of: the International Organization for Migration (IOM), the United Nations High Commission for Refugees (UNHCR), the International Labour Organization (ILO), the United Nations Populations Fund (UNFPA), the United Nations Human Settlements Program (UN-Habitat), the Agency Coordination Body of Afghan Relief and Development (ACBAR), and the University of Maastricht's Graduate School of Governance.

The opinions and analysis contained in the publication are those of the authors and do not necessarily represent the views of the Technical Working Group members.

Part 1 of this study should be cited using the following referencing style:

Samuel Hall (2016) 'Urban displaced youth in Kabul - Part 1. Mental Health Also Matters', Afghanistan.

Samuel Hall encourages the dissemination of its work and will normally grant permission to reproduce portions of the report promptly. For permission to photocopy or reprint any part of this work, please send your request, along with complete information, to development@samuelhall.org 


\title{
STAKEHOLDER FEEDBACK
}

\author{
From a WORKSHOP held in Kabul in OCTOBER 2014
}

The concerns on urban displaced youth are not new.

'We need to highlight issues related to migration and mental health. We need to ensure that government and partners invest in resources to provide the psychological counselling for this particular vulnerable group - as they themselves have voiced this need.'

- UNFPA Representative

'TVET is especially suitable for Afghanistan in that it will be developed in a competencybased training system. It will be focusing on learning how to do a job, rather than focusing on theoretical matters or subjects. In parallel, literacy and many essential skills will be taught. We can introduce validation of prior learning for people who have not benefited from education before or who acquired skills on the informal labour market sector.'

- ILO Chief Technical Adviser

'This is a conversation that started in August 2014 with ACBAR's regional refugee workshop and is now centring on the youth challenge.

When it comes to the specific issue of displaced populations, of returnees, we are seeing very significant numbers of youth being put in a very vulnerable situation... [They face] further challenges than the rest in finding jobs [and] livelihoods and therefore [they] become a potential target for recruitment, for violence, for criminality.'

The second biggest challenge is urban development. Many of the issues raised in this report happen at our doorsteps. Kabul was a place of about less than a million about 10-12 years ago, [but] today it is estimated at 6-8 million.

When we put these two trends together and we draw linkages - as done in this reportit becomes [not only] a priority for social development but also a clear humanitarian concern.'

- UNHCR Representative 


\section{Table of Contents}

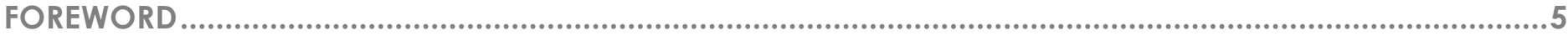

THE 15-24 YOUTH BRACKET \& THE TRANSFORMATION DECADE $2015-2024 \ldots \ldots \ldots \ldots \ldots \ldots \ldots \ldots \ldots \ldots \ldots \ldots \ldots \ldots \ldots \ldots . . . \ldots \ldots$

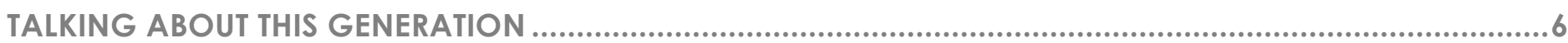

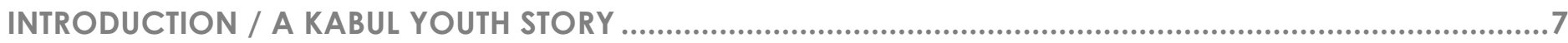

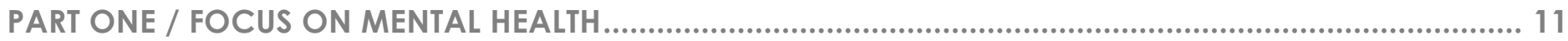

\section{Forthcoming:}

PART TWO / FOCUS ON EDUCATION, SKILLS AND JOBS

PART THREE / FOCUS ON POLITICAL \& SOCIAL INTEGRATION

RECOMMENDATIONS. Filling in A Void: The Lack of Assistance for youth

\section{ACRONYMS}

ACBAR - Agency Co-ordinating Body for Afghan Relief ANUDUS - Afghanistan National Urban Drug Use Survey

CAH - National Child and Adolescent Health Strategy 2009-2013

CRC - United Nations Convention on the Rights of the Child

CSO - Central Statistics Organization

DRC - Danish Refugee Council

DMOYA - Office of the Deputy Ministry of Youth

EU - European Union

EVI - Extremely Vulnerable Individuals

GIROA - Government of the Islamic Republic of Afghanistan

ICPD - International Conference on Population and Development

IDP - internally Displaced Person

ILO - International Labour Organization

IMC - International Medical Corps

INGO - International Non-governmental Organisation

IOM - International Organization for Migration

IPSO - International Psychosocial Organisation

$\mathrm{Mol}$ - Ministry of Interior Affairs

MoJ - Ministry of Justice

MoPH - Ministry of Public Health

MORR - Ministry of Refugees and Repatriations

MoUD - Ministry of Urban Development Affairs

MVI - Multi-dimensional Vulnerability Index

NGO - Non-governmental Organisation

NNGO - National Non-governmental Organisation

NRC - Norwegian Refugee Council

PSU - Primary Sampling Unit

PTSD - Post-traumatic Stress Disorder

RQA - Return of Qualified Afghans

TVET - Technical Vocational Education and Training

UN-DESA - United Nations Department of Economic and Social Affairs

UNFPA - United Nations Population Fund

UNHABITAT - United Nations Human Settlements Program

UNHCR - United Nations High Commissioner for Refugees

UNODC - United Nations Office on Drugs and Crime

WHH - Welthungerhilfe

WHO - World Health Organization 


\section{FOREWORD}

\section{THE 15-24 YOUTH BRACKET \& THE TRANSFORMATION DECADE 2015-2024}

Largely ignored for over 10 years, the role of Afghanistan's youth in transition has been increasingly in the spotlight since 2013, the year of the National Youth Policy. Much more needs to be done to bring change for youth as $60 \%$ of Afghanistan's population is under the age of 24. Taking the case of Kabul's urban displaced youth, this study shows just how.

If Afghanistan is to transition to a self-sustaining country, what will be the role of the next generation of workers, parents and leaders? To act on the promises of a Transformation Decade (2015-2024) and in line with the Tokyo Conference on Afghanistan, youth will need to be given a more central place in Afghan society. This is their wish - as laid out in this study by Samuel Hall, supported by IOM and with a Technical Working Group composed of UNHCR, UNFPA, ILO and ACBAR - and a testament to the untapped potential of Afghanistan's youth.

Investing in youth empowerment, education and employment are the three priorities laid out by the Deputy Ministry of Youth Affairs and UNFPA in Afghanistan. Adding evidence to these three key areas of focus, the present study highlights unaddressed gaps, namely the mental health needs among Afghan youth. In a country where $75 \%$ of the population has been displaced and where over 30 years of war has meant that not a single generation has known peace, there are to date no extensive psychosocial programs to support those who have suffered from conflict. In the world's largest protracted refugee situation, now moving into more of a mixed migration paradigm, no extensive program has been linked to mental health or psychosocial support for returnees and migrants. People cannot just return home - to a country at war or areas fresh out of conflict and resume a normal life. Imagine now, that in a country where such questions are taboo, respondents openly speak of needing mental health support - female and male youth alike. The demand is there, it should be seized as an opportunity.

The International Organization for Migration supports this sort of research that gives voice to the aspirations and expectations of a generation intent on being given a space and a voice to contribute to the reconstruction of their country. ${ }^{1}$

This study - presented in a four-part series - by Samuel Hall focuses on Kabul city - one of the fastest growing capitals in the world. I would encourage donors to support the extension of this research to other key Afghan cities to address the triple challenge of mobility, urbanization and the youth bulge. Fight or flight should not be the only options offered to youth - instead they should be supported and encouraged to make positive contributions to their homeland. After all, without them their country does not exist.

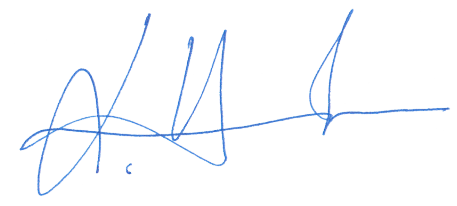

Laurence Hart

Chief Of Mission IOM Afghanistan

I Samuel Hall, "Afghanistan's Future in Transition: A Participatory Assessment of the Afghan Youth," 2013. 


\section{TALKING ABOUT THIS GENERATION}

Despite the constant increase in conflict across Afghanistan, to date urban settings remain economic and physical safe havens, at least in relative terms. What can the displaced hope to gain from settling in urban settings? What do specifically have the youth to hope for - what future does the urban landscape have in store for them? Wanting to integrate - or re-integrate - in new urban settings is the reality for youth. But how?

The urban landscape in Afghanistan is much more divided than it may at first seem, not only along ethnic or political lines, but also along the lines of migration and displacement. This research finds - as did previous research conducted by Samuel Hall - that the most vulnerable are internally displaced persons (IDPs) and forced returnees. An increasing number will never go 'home', to their parents' ancestral lands, to the villages where they were born, or to the provinces from which their families hail. Local integration is the hope for IDPs; and migration abroad, irregular and temporary, is often the preferred option for forced returnees.

More flexible approaches to durable solutions and to return and reintegration are needed. Firstly, understanding that it is often about 'integration' rather than re-integration. Youth and their households may not be well versed in the requirements of Afghan cities. They may not have the contacts or networks to secure jobs. As this three-part study reveals, youth mainly turn to community leaders and religious leaders for advice, as they consider their parents ill-equipped to support them. The usual nuclear family support does not play its role in integrating displaced youth locally. Other actors step in - youth themselves voiced their concern over growing criminality, the role of gangs and daily harassment including police harassment, and an overall climate of terrorism and political insecurity.

They seek to find their place in society, to become the economic, social and cultural leaders they want to be. The challenge is to adapt to the reality of Afghan urban displacement. There are still too many unknowns and under-explored areas. This study focuses on these: mental health needs; skills, education and employment needs; and social integration and inclusion.

Creating a place for the displaced is a priority. The Kabul case study presented here is a first attempt at defining such a place. This study reveals the invisible trauma of conflict on the young generation, the geographic boundaries and borders within a city that divides neighbourhoods and limits options offered to youth, the marginalization and isolation of the displaced youth in particular who suffer from mental health needs that are now increasingly being voiced, and the rise of criminality and urban insecurity that make all especially female youth - insecure.

Over the past five years, we have worked with a range of organisations to increase evidence-based field research. We continue with this research to address key gaps: gaps in youth-based evidence and programming, gaps in mental health evidence and programming, and lastly, gaps in understanding the nuances of return, displacement and integration. Beyond blanket solutions, a local neighbourhood approach to supporting youth will bring the greatest results.

This is Part one of a three-part series to be released in June, July and August 2016 ahead of the Brussels Conference on Afghanistan (October 2016). It is our hope that this evidence base will inform policy and political discussions. 


\section{INTRODUCTION / A KABUL YOUTH STORY}

\section{RATIONALE AND METHODS}

This first representative survey of Urban Displaced Youth (15-24 years) in Kabul presents the challenges faced by youth displaced by a life of conflict, natural disasters, and economic hardships. This large-scale survey of 2,006 youth in Kabul includes representative sub-samples of returning refugees, returning migrants, internally displaced persons (IDPs), rural-urban and non-migrants, to account for the diversity and nuances of migration experiences among the population, taking displacement as a key lens through which to understand Kabul's future. Kabul is witnessing an increase in insecurity, yet remains a main hub towards which populations gravitate from rural areas, from conflict, and from abroad. This presents the challenge of limited absorption and strained resources leading to growing tensions.

Why focus on migrants and the displaced? Preventing a social time bomb. Migration is a social time bomb in a country where the combination of forced and voluntary, internal and international migration, in- and outmigration, is testing the absorption capacities of urban hubs. Urban centres are marked by an annual growth rate of $5.4 \%$ and a doubling of the population over the next seven years. ${ }^{2}$ In only six years, Kabul city experienced a three-fold population increase from 1.5 million in 2001 to 4.5 million in 2007, growing to an estimated 5 million people today. It has been termed 'one of the fastest growing cities in the region.' 3 Afghanistan's centres will continue to expand with rural security and living conditions deteriorating across the country. Over $40 \%$ of the population is under 15 and almost two thirds under 25 , leading to a youth bulge, a situation where the proportion of young people is significantly larger than older age groups.

Why is it important to talk of youth? Targeting the next generation of leaders. Since $76 \%$ of Afghans have experienced displacement at one point in their lifetime, assessing the impact of migration on wellbeing is particularly relevant to the Afghan context. Taking this statement a step beyond, Afghanistan's migration is youth-based, yet they are the least understood. In Afghanistan, youth migration is defined by three traits: its irregularity, its informality, and its failed attempts at (re-)integration. The most successful have been voluntary and assisted returning refugees - while others, including voluntary return migrants, forced returnees (deportees) and IDPs, remain the most vulnerable. Yet, with intensified conflict, the numbers of IDPs in Afghanistan has doubled in just three years, exceeding the 1.2 million mark in 2016 with growing vulnerabilities for minors

Why is this research important? Identifying opportunities for action. Afghanistan's displaced youth are a left-out category in terms of the assistance received. There are increasing pressures for Afghan youth to return home whether from refugee/migrant-hosting, asylum-providing or host country communities. Pressure to return, but to return to what? Every year, about 400,000 youth with limited skills enter the labour market, mostly in urban centres. The current demand for labour and shortage of employment opportunities form a strong pull factor, which means many are opting to leave if they can. There is a demographic pull for youth to leave and an insecurity push for youth to 'fight or flight', a common dichotomy in conflict settings. How can youth be supported to contribute positively to their society? This study voices their needs and concerns and identifies opportunities for action specific to Kabul. The local tensions highlighted in this study require local - and neighbourhood level - solutions to integrate youth in their everyday Kabul society.

2 FoAC, "Opportunities with Options: Scenarios for Guiding Urban Growth 2015-2050," Series Two, May 2016.

3 Jo Beall and Daniel Esser, "Shaping Urban Futures: Challenges to Governing and Managing Afghan Cities" (AREU, March 2005). 


\section{ON METHODS: CAPTURING MIGRATION EXPERIENCES}

Conceptually, this research is fundamental as it concentrates on three key concepts and policy priorities: i) the youth dimension, ii) the migration dimension and iii) the urban dimension. Three research questions reflect this nexus:

1. Youth profiles: What are the determinants of wellbeing for urban displaced youth?

2. Impact of migration on youth: How does migration influence youth's wellbeing?

3. Urban stability: How can urban displaced youth be a stabilizing/destabilizing urban force?

Methodologically, a multi-dimensional vulnerability index (MVI) is used to compare living conditions within each category and between categories across the different dimensions that impact wellbeing. The methodology identifies vulnerabilities within each youth category (e.g. identifying the most vulnerable within the returning refugee category) while it will also provide a comparative assessment across groups (e.g. are returnees, deportees and IDPs more vulnerable than the non-migrant urban youth? Which category is the most vulnerable? How can programming responses be tailored?). This requires two correlated approaches:

First, a comparative lens with equal samples of displaced and migrant youth categories covers returning refugees, returning migrants, internally displaced persons and rural-urban migrants. Thus, it includes both forced and voluntary dimensions, as well as international and domestic dimensions. In addition, a sample of nonmigrants has been included as a control group to test hypotheses on migration's impact on wellbeing.

Second, in the final chapters of this study, a selected Multi-Dimensional Index will be presented reflect deprivations in five dimensions that have an impact on poverty:

- Dimension 1: Economic

- Dimension 2: Education

- Dimension 3: Health

- Dimension 4: Housing \& Environment

- Dimension 5: Social Capital

\section{Quantitative Data}

Table 1 shows the breakdown of the final sample by migratory status. The target of 400 respondents was set per group to provide a statistically representative sample.

Table 1: Migration Status of Respondents

\begin{tabular}{|lcc|}
\hline Migrant Category & Frequency & Percentage \\
\hline Refugee Returnee & 398 & 20 \\
\hline Return Migrant & 399 & 20 \\
\hline Assisted Voluntary Return & 281 & 14 \\
\hline Forced Return / Deportation & 118 & 6 \\
\hline Internally Displaced Person & 419 & 21 \\
\hline Rural-Urban Migrant & 399 & 20 \\
\hline Non-migrant (No Migration Or Displacement Experience) & 391 & 19 \\
\hline \hline Total & 2006 & 100 \\
\hline
\end{tabular}

The quantitative data were collected in two phases in November and December 2013 using a grid approach to divide Kabul into 56 Primary Sampling Units (PSUs). This approach ensured that all socio-economic categories across central, northern, southern, eastern and western Kabul city were covered. This included formal and informal settlements as well as a range of accommodation types. The field teams covered all 56 locations in 28 days based on the following sampling methodology: 
1. Phase 1: Random sampling ( 14 days): The first half of respondents $-1,000$ respondents - were randomly selected. The two field teams (each composed of six field staff) surveyed 28 PSUs in 14 days.

2. Phase 2: Quota / Purposive sampling (14 days): A quota system was used mid-way to adjust and ensure that sufficient targets were reached within each of the sub-groups.

The aim of the sampling methodology is to provide a representative sample of youth. The second phase quota imposed the number of respondents in each migration category - no other quota was sought to ensure representativeness. The sampling plan covered both active and inactive youth in their homes. In each PSU, the field teams first reported to the local community leader. After an initial introduction of the research objectives and authorization, the team then started from a landmark - a mosque, school or community centre - and selected every other third home or office location, in different patterns for each team member to avoid overlaps. At the door, the interviewer spoke with someone between the ages of 15-24. With this process, interviewers completed six questionnaires per day for a total of two teams covering 56 PSUs in 28 days.

\section{Callbacks}

In 2016, the research team conducted callbacks with the sample interviewed in 2013. 40\% of the original sample agreed to respond a select number of questions per dimension. The results from the callbacks will be presented in Part three of this research to conclude with an updated analysis.

\section{Qualitative Data}

The qualitative data complement the analysis of the quantitative survey. Focus groups, case studies and key informant interviews were conducted in the same PSUs by the research team, with male and female respondents separately. The qualitative fieldwork included $\mathbf{3 0}$ focus group discussions and case studies with:

- Returning refugee youth

- Returning migrant youth (both voluntary returnees and deportees)

- IDP youth

- Rural-urban migrant youth

- Non-migrant youth (control group)

20 Community leader interviews - Community leaders are a necessary 'rite of passage' for researchers. Upon arrival in a community, research teams present the object of their study and letters of authorisation. Community leaders provide the necessary seal of approval to ensure participation and guarantee security and cooperation.

Field observations - A field report was provided for each PSU visited by the research team. These qualitative reports provide information about the context and the particularities of each surveyed location. The field reports were implemented to go deeper into the analysis of the situations of youth in each area.

\section{Limitations and Constraints}

Survey fatigue - Interviewers encountered respondents who refused to participate in 'yet another survey'. This was particularly interesting to see in the case of girls, where researchers were not limited by parents prohibiting their daughters to partake due to cultural beliefs or stigmas associated with talking to strangers, but rather respondents themselves expressing their discontent about the lack of positive outcomes for participants and their communities of past surveys.

Overlap of migration categories: The multiplicity of migration experiences - Categories are not as easily distinguishable as would have been ideal from a sampling perspective. Returning refugees became internally displaced or had returned from exile with their families before migrating alone abroad and ultimately being deported. Such overlaps are the norm rather than the exception. The research team used the migration experience that defined the largest chunk of the respondents' lives as the qualifying criteria. This impacted both quantitative and qualitative surveys. 


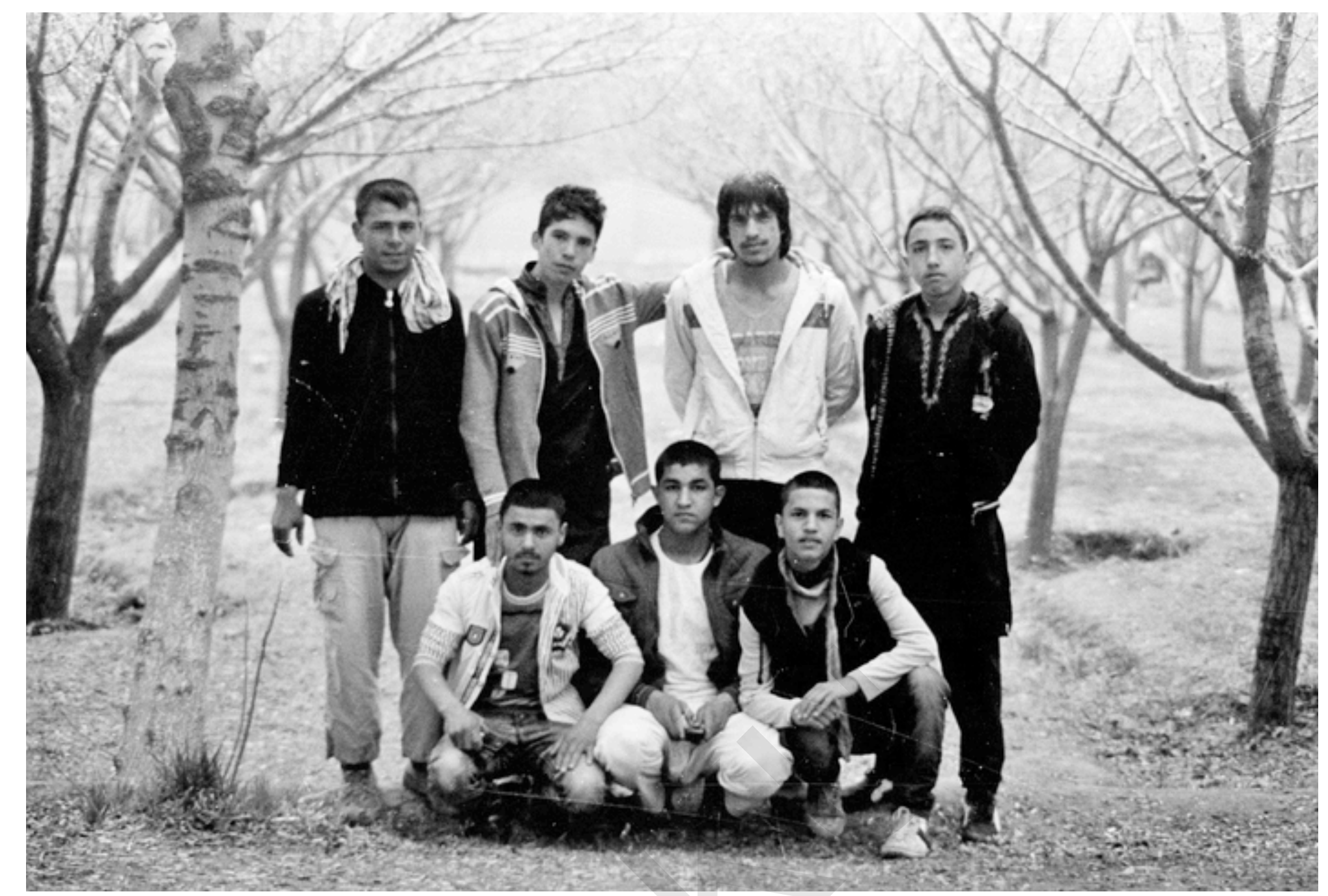

URBAN DISPLACED YOUTH IN KABUL Mental health matters 


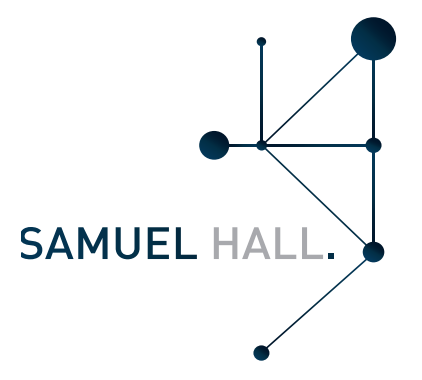

\section{CHAPTER ONE / FOCUS ON MENTAL HEALTH}

\section{URBAN DISPLACED YOUTH IN KABUL Mental health matters}

\section{INVESTING IN MENTAL HEALTH: A NATIONAL PRIORITY}

The findings of this study strongly advocate for a paradigm shift. The alarming mental health situation of the Afghan youth should not be considered as a secondary individual health issue anymore, but as an actual threat to any possible social, economic and political development in the country. As highlighted in a UN-DESA report, 'mental-health conditions have a significant impact on the development of (...) youth and their social and economic integration, including employability'. ${ }^{4}$ This is true of youth - and even more of the displaced youth.

Most stakeholders interviewed argue that stigmatisation of mental health prevents: 1) those affected from seeking support from the few existing institutions; 2) Afghan society from acknowledging the issue; 3 ) and local decision-makers from actually dealing with it. While accurate, this analysis misses the other side of the coin: mental health is not widely popular among donors, as 'the tangible value for money of mental health projects is technically difficult to assess'. ${ }^{5}$

After an almost two-year research process, this research confirms that mental health situation of the Urban Displaced Youth should - finally - be considered an emergency by all the national and international stakeholders. It is now time for action.

\section{SYNTHESIS}

The authors of this report have analysed the stigmatisation that negatively impacts the displaced: the experience of stigma is probably the most difficult social and psychological issue confronting deportees. This research confirms this finding and the vulnerabilities of deportees and internally displaced youth specifically. The process of stigmatisation keeps these groups marginalised and locally-bound in a shrinking geographic, social, economic and political space that naturally impacts their own self-perception and their overall mental health. Lack of psychosocial wellbeing is a key threat to the stability of the displaced and to reaching durable solutions. Socio-economic separation is a major effect of stigmatisation that impacts the present and future of the displaced.

This study shows that youth with no migration background present much healthier profiles on average, while return migrants and especially IDPs find themselves the most vulnerable. A large majority (70\%) of young Kabulis have experienced traumatic experiences (one or multiple shocks that include not only personal traumas, but also criminal or terrorist related issues). According to the Health Index developed in this study, IDPs remain more than a third more likely than youth with no migration background to be deprived from basic access to healthcare, and deportees more than $50 \%$ more likely. Deportees are by far the worst off.

The last section presents practical recommendations to both the Afghan government and the international community.

4 UN Department of Economic and Social Affairs, "Mental Health Matters: Social Inclusion of Youth with Mental Health Conditions," 2014.

${ }_{5}^{5}$ Medical aid worker in Kabul, Key Informant Interview, May 2015. 


\section{National situation at a glance}

In a country where $63 \%$ of the population is below the age of 25 , the health and well being of adolescents and youth will partly determine the country's economic and social future.6 However, while health has been one of the priorities on both international and national agendas, psychosocial problems or mental disorders have been largely under-estimated and under-addressed - if not ignored. A WHO survey conducted in 2004, the last available, found $68 \%$ of respondents suffering from depression, $72 \%$ from anxiety and $42 \%$ from post-traumatic stress disorders. ${ }^{7}$ More than ten years later, Afghan youth are still exposed to conflict, insecurity, domestic violence, extreme poverty, gender disparities, displacement and other potentially traumatic experiences. Yet no data exist on the needs of the displaced.

While the needs are significant - in a country where symptoms associated with post-traumatic stress disorders affect the majority after decades of conflict - the country still suffers from the lack of trained professionals (psychiatrists, social workers, psychologists) and adequate infrastructure and awareness about mental health conditions. A rapid comparison between Afghanistan and its neighbours, as emphasized in the graph below, presents a particularly grim picture of the country, with only one tertiary health facility (Kabul Mental Health Hospital), approximately three trained psychiatrists and ten psychologists 'covering' a population of more than 30 million people. 8

Figure 1: Number of trained mental-health workers in 2014 (per 100,000 population) Source: WHO Global Health Observatory Data Repository

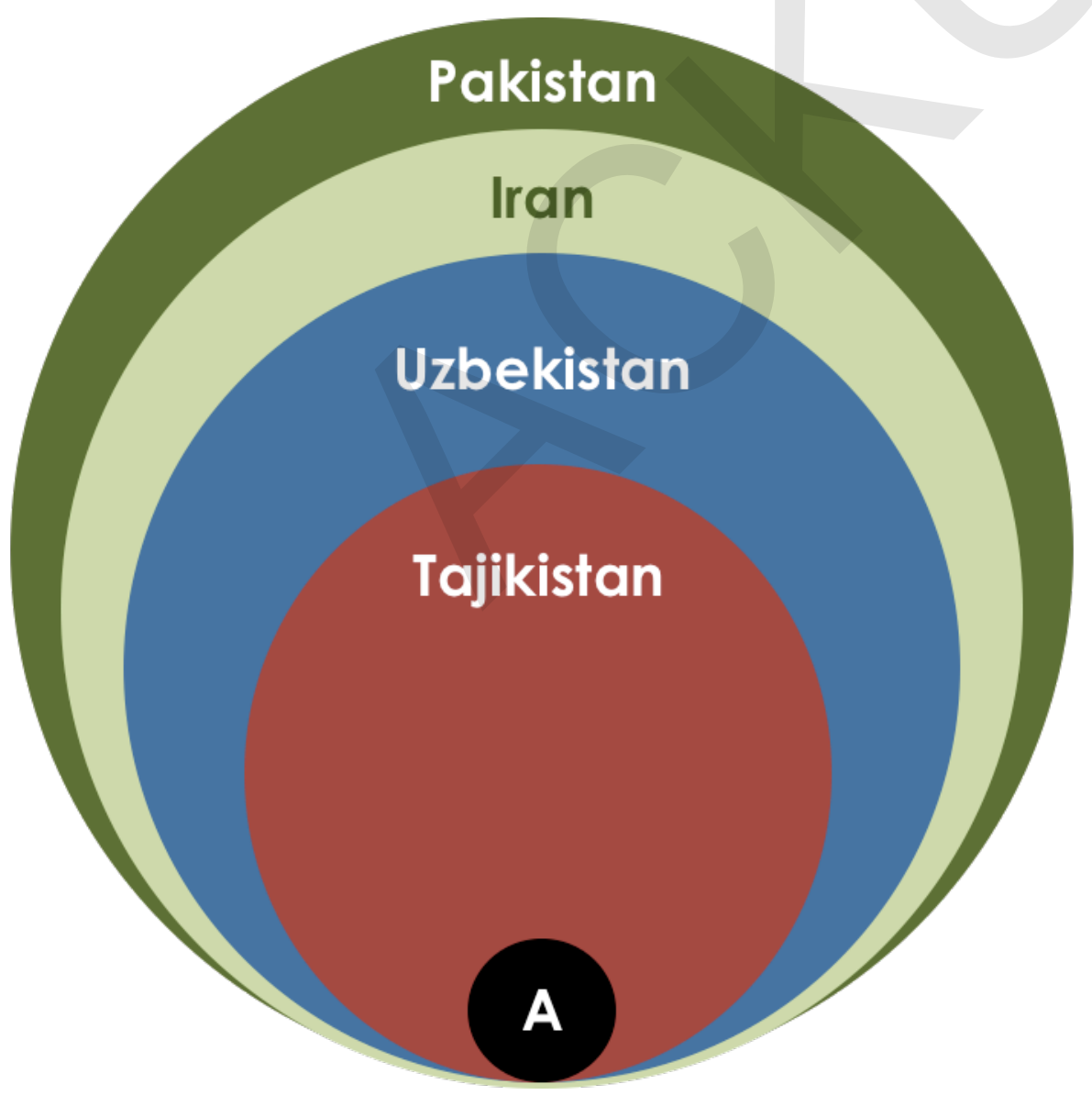

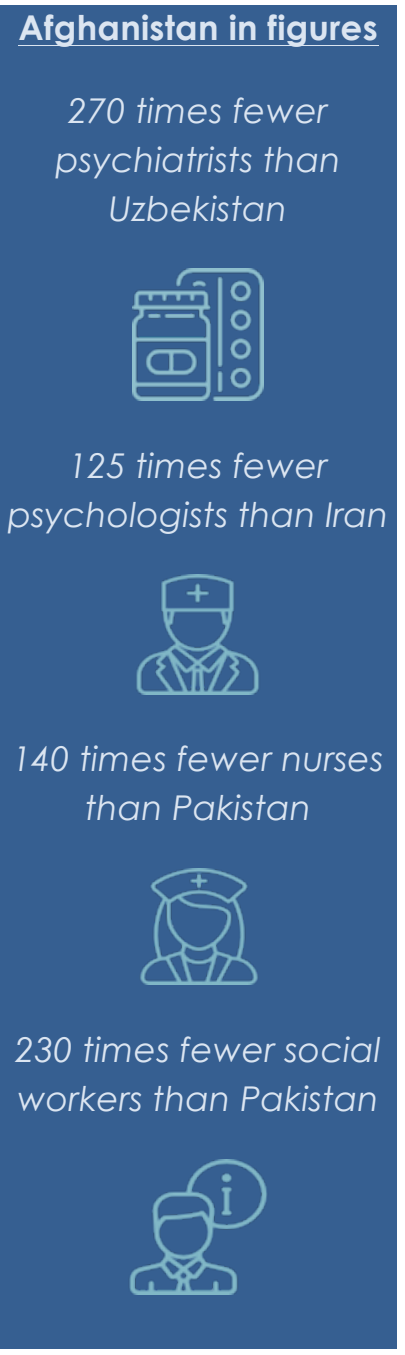

\footnotetext{
"Central Statistics Organization, "National Risk Vulnerability Assessment 2011-2012" (Kabul: CSO, 2014).

7 WHO and Ministry of Public Health, "WHO-AIMS Report on Mental Health System in Afghanistan" (Kabul, 2006).

8 WHO, "Global Health Observatory Data Repository: Afghanistan," 2014.
} 


\begin{tabular}{|lcccc|}
\hline & Psychiatrists & Psychologists & Nurses & Social Workers \\
\hline Pakistan & 0.31 & 1.09 & 15.43 & 2.32 \\
\hline Iran & 1.76 & 5.07 & 8.84 & 0.72 \\
\hline Uzbekistan & 2.68 & 0.02 & 8.96 & 0.02 \\
\hline Tajikistan & 2.16 & 0.01 & 7.14 & NA \\
\hline Afghanistan & 0.01 & 0.04 & 0.11 & 0.01 \\
\hline
\end{tabular}

\section{Policy framework: theory and practice}

Afghanistan is a signatory to the Programme of Action of the International Conference on Population and Development (ICPD) and the United Nations Convention on the Rights of the Child (CRC). Afghanistan is committed, therefore, to provide the underlying conditions for health and to develop policies and plans that address the main determinants of health that affect young people, including health-related behaviour and their impact on health at later stages of life.

However, young people are not adequately reflected in Afghanistan's national health policies. In Afghanistan, the main strategic document in terms of young people's health is the Child and Adolescent Health (CAH) Strategy 2009 to 2013.

Due to an increased understanding of the demographic significance of young people - and their potential for sustainable development of the country - the MoPH has developed a National Health Strategy for Young People. This decision is further reflected in Afghanistan's National Youth Policy, which was developed with the involvement of $\mathrm{MoPH}$. The document provides recommendations in the area of adolescent and youth health including specific reference to developing a national health strategy for young people.

Initial recommendations for the National Health Strategy for Young People were developed at the National Youth Strategy Conference, which took place in December 2013 in Kabul. The conference brought together an expert panel on adolescent and youth health that comprised representatives from the Government, civil society, health sector NGOs, youth representatives and international community.

So far, however, international and non-governmental development organisations have generally ignored mental health, particularly among youth. Some initiatives are nonetheless worth mentioning. In 2011, the NGO Afghanistan Libre implemented a psychosocial assistance programme in the province of Paghman, focusing primarily on women and children, which led to 'a strong buy-in from communities and significant improvements (...) even if donors do not understand why it is a priority' (NGO, field officer, February 2015). In line with the National Mental Health Strategy of the Afghan Ministry of Public Health, the European Union (EU) has provided 7 million euros to mental health programmes in Afghanistan (International Medical Corps) and supported the International Psychosocial Organisation (IPSO) to train 140 psychosocial counsellors in 34 provinces. The IMC-led initiative, in partnership with the MoPH, was clearly successful in improving knowledge and changing attitudes to treatment and care among Afghan psychiatrists, trainee doctors, psychologists, psychiatric nurses and social workers. Interviews conducted in February 2016 with five former trainees confirm the relevance of this training programme: "We knew that there are only a few of us in Afghanistan. Thanks to the training we received, we also realised that we did not have enough knowledge and updated treatments for our patients. So both the quality and quantity need to be addressed in this country' (Occupational therapist, Kabul, February 2016). However these positive milestones are only drops in the ocean and this study calls for immediate and longerterm action.

According to the key informant interviews conducted with governmental officials as well as international stakeholders, there are several obstacles to implementation by national and international actors: lack of 
information and awareness, absence of strategic guidelines, poor interagency collaboration, almost inexistent funding allocation and finally, technical and medical resource limitations. For most Afghan institutions, even in Kabul, socio-cultural stigma also constitutes a strong barrier to awareness-based methods and programmes.

\section{Key findings:}

- The physical and mental health situation of Afghan youth is a matter of significant political, social and economic concern, but this issue is often invisible or unseen - especially as it affects the most vulnerable, the displaced and the migrant.

- The existing policy framework remains to be implemented, with sustained efforts by DMOYA, MoPH (GIROA) and WHO, UNFPA (UN). There is a need for a stronger political impetus to turn recommendations into practice.

- Health issues affect people differently depending on vulnerability variables. This chapter focuses on displaced and migrant youth while highlighting other specific variables such as gender and literacy.

\section{A Health and Safety Poverty Index: focusing on migrants and the displaced}

This section aims to draw a picture of the health and safety landscape of Kabuli youth using migration and displacement as critical lenses. To do so, access to health facilities, illness and injury prevalence, mental health and drug abuse were among the key indicators used to calculate a citywide health and safety poverty index. With an average of 11.2, scores ranged from a very healthy three to a very unhealthy, untreated, unsafe and threatened 26.

As shown in the graph below, youth with no migration background drive the average health and safety score down, presenting much healthier profiles on average, while return migrants and especially IDPs find themselves the most vulnerable once again.

- This confirms the findings of other recent studies conducted by Samuel Hall for IOM (2014) or NRC (2012): IDPs, and especially the 15-24 segment, fare worse than other migrant groups and a fortiori than nonmigrant groups in terms of health and safety. ${ }^{9}$

- A constant observation of this study, whatever the vulnerability or socio-economic dimension considered, is that the return migrant category hides stark differences between those who benefited from assisted voluntary return and those who were deported by force. With an average score or 12.2, return migrants do score slightly lower than IDPs, but return migrants are not a homogenous group. Deportees score much higher - and hence are much more vulnerable - than voluntary return migrants (14.0 vs. 10.4, which represents a $36 \%$ difference on the health and safety poverty index).

- These two findings from the quantitative survey clearly point to a recurrent observation made during most focus group and individual discussions with interviewed youth: deportees and IDPs have fewer socio-economic ties with local host communities and are de facto: i) less likely to access basic health and safety services, and ii) more likely to be exposed to safety hazards and health issues.

\footnotetext{
9 Samuel Hall, "Displacement Dynamics: IDP Movement Tracking, Needs and Vulnerability Analysis, Herat and Helmand" (Kabul, 2014); Samuel Hall et al., "Challenges of IDP Protection: Research Study on the Protection of Internally Displaced Persons in Afghanistan" (Kabul, 2012).
} 
Graphs 4-5: Mean health and safety poverty score in the five surveyed categories (focus on deportees)
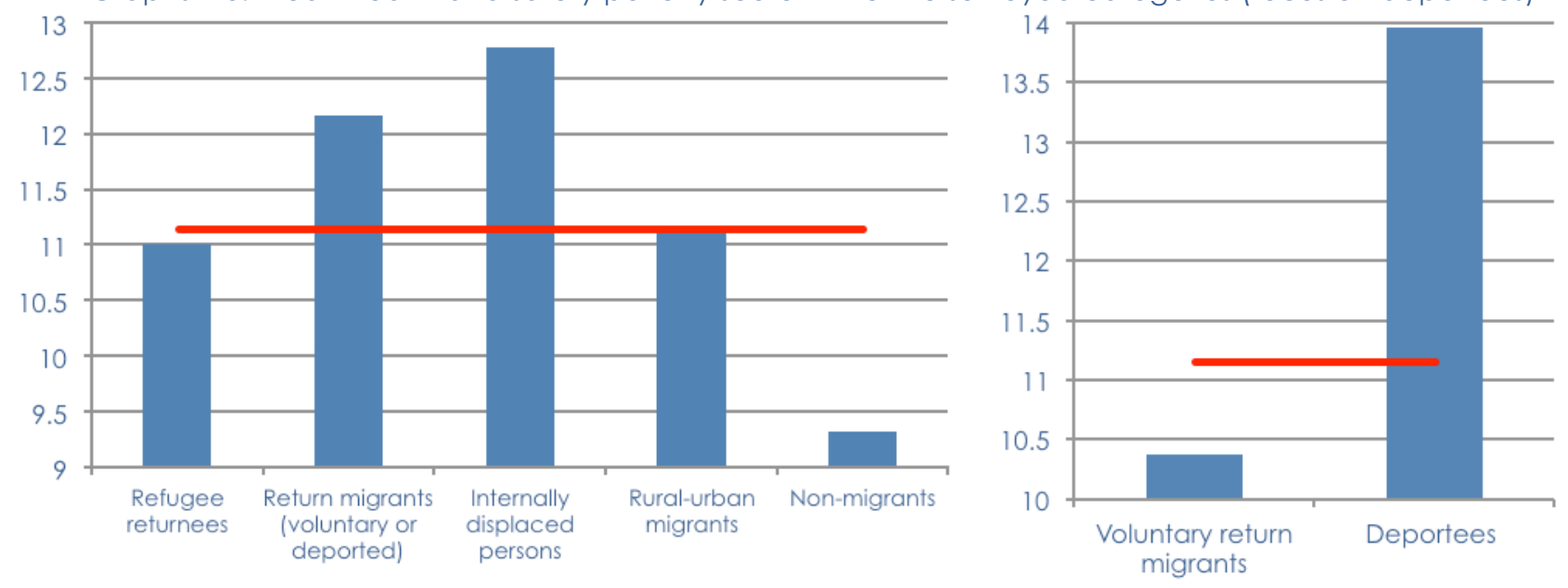

Health and Safety Vulnerability: IDP Communities' Recurring Extreme Vulnerability

Graph 3: Respondents who reported being sick or injured "over the past 3 months"

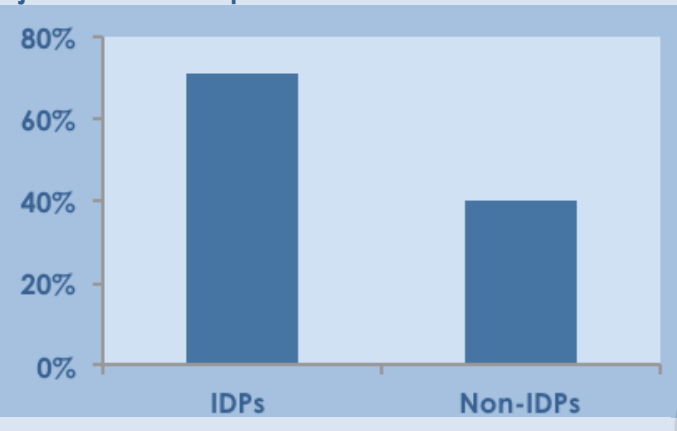

The Health and Safety Poverty Assessment of the Urban Displaced Youth confirms that IDPs generally fare worse than any other migrant category (except deportees or forced returnees). While this is clearly true of the health situation on the long-term, a snapshot of today's situation also corroborates this finding: while $71 \%$ of surveyed IDPs reported being sick or injured in the three months preceding the interview, "only" $40 \%$ of non-IDP respondents answered positively to this question. As suggested in the opposite report and case study, the health situation of IDP youth in Kabul is particularly critical, with cases of mental and chronic illnesses. It is both a demographic and social time bomb: social exclusion can kill you physically and mentally.

\section{Research Study on IDPs in urban settings}

(Commissioned by the World Bank, 2011)

The first rigorous work on the situation of IDPs in Afghan urban settings, this study shows that $66 \%$ of surveyed IDPs in Kabul, Kandahar and Herat were within the UNHCR Extremely Vulnerable Individuals (EVI) guidelines. The majority had significant physical, mental and social vulnerabilities, of which the most frequent was health related (chronically ill, mentally ill, physically disabled), followed by those lacking support of family or community members (poor families, female-headed households, single parent households, drug addicts). Although the study had not confirmed any clear pattern in terms of EVI category by duration of settlement, some significant differences were observed between the three cities in the study: 'IDP households surveyed in Kabul, in particular, are more likely to fall in EVI categories. Higher concentration of vulnerable households could be a direct consequence of the self-selection of IDPs who choose to locate in Kabul because of better access to services in the capital.'

\section{Interview with Zabihullah, in Sare Tapeh, Karte Naw, August 4, 2015}

Male, 19, Married, Illiterate originally from Geresha (Helmand)

Zabihullah arrived in Kabul with his family in 2012. They left Helmand due to regular clashes between Taliban insurgents and governmental forces: 'Here, I work as a daily worker in the construction sector, but it has become more difficult to find jobs for illiterate people and there are more and more jobseekers. All my family 16 people) lives with my salary, at most 5,500 AFA a month, which is not so bad in our community. But we spend more than I earn and we have a lot of debts to repay to relatives, shopkeepers and neighbours. (...) There is only one clinic nearby but the doctor and nurses are too busy. They cannot cure us. They don't have the time or the resources for people who cannot pay. Two years ago, I had some serious back problems but I don't know anyone out of my community in this city, even after 3 years. And when people are in moral pain and get sad or violent, we have no solutions here.'

\section{Key findings:}

- Youth with no migration background drive the average health and safety score down, with much healthier profiles on average, while return migrants and especially IDPs find themselves the most vulnerable.

- IDPs remain more than a third likely to be deprived, and deportees more than half.

- The return migrant category hides stark differences between those who

- Benefited from assisted voluntary return and

- Those who were deported by force, who are worst off by far. The situation of deportees is alarming in today's Afghanistan, raising the question of the political responsibility of the countries that send them back. 


\section{The invisible trauma: life experiences}

Very little is known about the state of mental health of young people in Afghanistan, but available research suggests that a large segment of Afghan adolescents and youth suffer from untreated mental health issues resulting from trauma and stress relating to conflict, displacement, poverty and continued insecurity. A representative survey on mental health in Afghanistan conducted in 2004 found that around $44 \%$ of respondents had experienced more than four traumatic events in the preceding ten years, $72 \%$ suffered from anxiety, nearly $68 \%$ reported some form of depression and $42 \%$ had post-traumatic stress disorders. 10

\section{Mental disorders: Symptoms of stress and trauma among urban youth in Kabul}

A major concern about urban displaced youth in Kabul and Afghanistan more generally is their mental health, due to the difficult life experiences they go through at a young age. A large proportion of youth in our sample has been affected by one or more shocks. Only $29 \%$ indicated never having experienced an event that could cause psychological problems. The remaining 1,421 respondents encountered at least one of the life experiences presented in the table below.

Table 2: Traumatic Life Experiences of Respondents

\begin{tabular}{|lll|}
\hline Life Experience & $\mathrm{N}$ & $\%$ \\
\hline Loss of a close family member & 671 & 33.4 \\
\hline Firing, shelling & 623 & 31.1 \\
\hline Seen dead or wounded people & 613 & 30.6 \\
\hline Violent community dispute & 503 & 25.1 \\
\hline Moving to a new location (in the same country) & 424 & 21.1 \\
\hline Loss of a friend & 346 & 17.3 \\
\hline Moving to a new location (crossing a border) & 310 & 15.5 \\
\hline Loss of a home / home destroyed / evicted & 309 & 15.4 \\
\hline An argument with a friend & 292 & 14.6 \\
\hline Bombing & 173 & 8.6 \\
\hline Witnessing killing & 172 & 8.6 \\
\hline Believed I would die & 153 & 7.6 \\
\hline An argument with a family member & 126 & 6.3 \\
\hline Extra work or being overscheduled & 113 & 5.6 \\
\hline Torture & 98 & 4.9 \\
\hline Not knowing if family members or friends are alive & 63 & 3.1 \\
\hline Forced labour & 37 & 1.8 \\
\hline Abduction & 20 & 1.0 \\
\hline
\end{tabular}

Youth speak of the presence and high visibility of the main forms of urban violence that are a result of common occurrences around them and not stand-alone events: theft, gangs, terrorist attacks/bombings and police (and other forms of) harassment. A mix of criminality and terrorism weighs in on urban displaced youth who find themselves secluded further in neighbourhoods or vulnerable to recruitment in gangs. Although the phenomenon of recruitment to terrorist groups was not mentioned, respondents spoke of rising criminality and pressures on youth to join.

10 Barbara Lopes Cardozo et al., "Mental Health, Social Functioning, and Disability in Postwar Afghanistan," JAMA 292, no. 5 (August 4 , 2004): 575, doi:10.1001/jama.292.5.575. 
- The rise of criminality in Kabul is a concern that urban displaced youth did not feel as strongly in the past - they are both victims and targets as members of such groups.

- Verbal harassment is the highest form of urban violence raised by youth respondents in Kabul - with $15 \%$ having experienced verbal harassment as opposed to $12 \%$ for physical beatings. Women are notably more vulnerable to verbal harassment in the streets, which they link directly to the lack of access to educational and job opportunities.

- Community disputes in Kabul rank high as a result of the above two trends, with almost one in five youth (equally split between men and women) complaining about such disputes. The qualitative data shows that these disputes are most often caused by the mix of ethnicities and tribes in neighbourhoods, the rise in criminality and gang-like behaviours related to drugs, and the lack of geographic mobility.

- Forms of sexual harassment, assault, abuse and exploitation are under-reported due to cultural taboos and victims' inability to speak up. Although over half of respondents agree on their concern about urban violence, female respondents overwhelmingly remain concerned about urban violence - well ahead of men. This corroborates the findings of the 2012 Heinrich Böll Stiftung security and safety audit in Kabul, which revealed two main concerns amongst women: suicide bombers and harassment. 'Both have an impact on how women use (or avoid using) public space. When

Table 3: Concern about urban violence by gender (in \%)

\begin{tabular}{|l|c|c|c|}
\hline & Male & Female & Total \\
\hline I am concerned & 56.03 & 70.83 & 62.76 \\
\hline I am not concerned & 43.97 & 29.17 & 37.24 \\
\hline \hline Total & 1094 & 912 & 2006 \\
\hline
\end{tabular}
asked about their biggest fear when out on the streets, $68 \%$ of women responded with suicide bomb. (...) Although the risks associated with harassment are less severe than those of a suicide attack, the everyday threat of harassment creates considerable anxiety amongst women'. ${ }^{11}$

Lack of research and data on mental health

The lack of psychosocial infrastructure and high quality data on mental health conditions in Afghanistan presents challenges in assessing the psychological status of the Afghani population. While data obtained in this study suggest a likelihood of such conditions as Post-traumatic Stress Disorder (PTSD), for instance, the inability to undertake official diagnostic assessments undermines analysis of vulnerabilities faced by Afghani displaced youth. Throughout this study, the researchers have thus focused on negative psychological symptoms as opposed to disorders. However, the researchers call for further research endeavours to assess the prevalence of mental disorders across Afghanistan's urban displaced youth population.

1 Samuel Hall, "The Challenge of Becoming Invisible: Understanding Women's Security in Kabul" (Kabul, 2012). 


\section{Consequences of symptoms from trauma and overall lack of coping mechanisms}

The consequences of such stress and trauma are that youth find it:

- Harder to do daily tasks (34.3\%)

- Harder to keep a personal routine $(32.4 \%)$

- Harder to sleep (31.4\%)

- Harder to eat (22.6\%)

- Harder to concentrate (20.1\%)

- Harder to control their anger (17.7\%)

- Harder to avoid tensions with family and friends (18.5\%)

In focus group discussions, the majority of participants indicated suffering from symptoms of trauma, such as getting angry easily or flashbacks. Stress due to socio-economic problems, the insecurity in Afghanistan and the inability to pursue further education were very common among the respondents. For females the lack of mobility is an additional stress factor - combined with already existing mental health problems, daily stressors, demanding living conditions and domestic violence - which puts an exceptionally high burden on Kabuli young women.

\section{When displaced youth in Kabul speak about mental health:}

'Sweating, bad dreams, difficulties sleeping, getting angry fast...I have flashbacks. My mind does not work anymore, I grew up in war.' - IDP youth

'I am stressed over the fact that I cannot go to town when I want, [and] I feel scared going outside. There is a lot of drug trafficking and criminality here these days, and then in the city, there is always the risk of bombings.' - Female returnee youth

'I stress over the economy. It affects my ability to go to school: we need books, proper and safe transportation, clothes. These are our daily concerns. What car will I get to go home after school? I have to wait sometimes 1 hour until I find a car for 5 Afghanis and not the 20 Afghanis most ask for this route. I have to wait in the street until I find a car. There is a risk of bombings, permanent traffic, 20 cars who stop and people who bother us... When you wait for 1 car, you have 20 others who come talk to you for nothing, harassing you... it is tiring.' - Female focus group participant, 19 years old

Table 4: Symptoms of Stress and Trauma Among Youth

\begin{tabular}{|lcc|}
\hline Symptoms of stress and trauma & $\mathrm{N}$ & $\%$ \\
\hline None & 946 & 47.2 \\
\hline Getting angry easily & 721 & 35.9 \\
\hline Feeling depressed & 712 & 35.5 \\
\hline Feeling tense, stressed out or anxious & 583 & 29.1 \\
\hline Feeling strong guilt or worry & 427 & 21.3 \\
\hline Bad dreams & 374 & 17.3 \\
\hline Feeling emotionally numb & 302 & 15.1 \\
\hline Difficulty sleeping & 217 & 10.8 \\
\hline Racing heart & 207 & 10.3 \\
\hline
\end{tabular}

\section{Key findings:}

- A large majority (70\%) of young Kabuli have experienced traumatic experiences (one or multiple shocks: not only personal or family traumas, but also criminal or terrorist issues)

- Challenges are often very local for Kabul's youth. They are not the most concerned with violence in general in Kabul - but in violence in particular in their immediate surroundings. Their interactions remain localised.

- Responses to these concerns - whether by improving relations between the police and youth or between different migrant, displaced and local resident groups - have to be treated at the local level. 


\section{Coping with mental health and trauma issues}

The dramatic absence of mental health experts in Afghanistan has often been highlighted. ${ }^{12}$ When asked about their coping strategies, respondents highlighted a mix of strategies. Importantly, youth reported that their problem was most often not discussed or solved within their household. Instead, they felt more comfortable turning to their religion or to community elders for help. This trend highlights three key determinants for youths' coping strategies:

1) Youth see their problems as collective and not individual, revolving around social issues, fights, criminality or conflict

2) Youth suffer from their household's lack of connections. They link the economic issues they suffer from directly to a lack of connections, which their households cannot solve as they suffer from the same constraint. This is especially true among the displaced who chose to settle in urban settings: whether returning refugees, IDPs or deportees, the displaced had less social networks to find adequate employment or proper training.

3) Youth need a space to discuss their problems, outside of their homes, and the only spaces (both spaces of recognition and of dialogue) available to them are either the local community centres or mosques.

'My parents have enough to handle, and they would not know how to advise me. I have to help them out of this situation. It is my responsibility. I am talking to some of the elders here in my neighbourhood, am hoping they will guide me'

Sohail, 24, returnee

Specific coping strategies can be supported by external actors - by providing more opportunities to rely on recreational activities, health providers and youth groups as coping mechanisms in times of stress and heightened trauma. These are settings in which specialised counsellors and stakeholders can deliver messages, training and positive coping strategies for the youth to gradually step out of their displaced-induced isolation. Looking at gendered differences in coping mechanisms, twice as many female youths felt that they had no coping mechanisms to deal with their stress and trauma. Many more women - one in ten - stayed home, feeling that they had no outlet for their stress. The positive impact of recreational activities is often restricted to male youth, with men being four times more likely to have access to recreational activities than women.

Female youth tend to rely more on third-party support than males - whether health providers or religious leaders. Although largely a taboo or unknown issue in Afghanistan, one in five respondents (19.5\%) stated needing psychological or psychosocial support. This was particularly true for women: almost one third of female youth ask for psychological support as opposed to one in ten male youth.

Table 5: Coping with stress: Coping strategies of youth by gender

\begin{tabular}{|lccc|}
\hline Coping mechanisms & Male & Female & $\%$ \\
\hline Support from family & 28.9 & 49.3 & 39.1 \\
\hline I pray & 28.9 & 19.8 & 24.3 \\
\hline Support from friends & 24.6 & 2.4 & 13.5 \\
\hline No coping mechanism & 4.9 & 10.1 & 7.5 \\
\hline I stay at home & 0.6 & 10.6 & 5.6 \\
\hline Recreational activities & 8.3 & 2.6 & 5.5 \\
\hline Other & 3.2 & 0.2 & 1.7 \\
\hline Support from health providers & 0 & 2.4 & 1.2 \\
\hline Support from religious / community leader & 0 & 2.4 & 1.2 \\
\hline Support from a youth group & 0.6 & 0 & 0.3 \\
\hline I have decided to leave / migrate & 0 & 0.2 & 0.1 \\
\hline Total N=1060 & 100 & 100 & 100 \\
\hline
\end{tabular}

12 See, for instance, Sarah Ayoughi et al., "Provision of Mental Health Services in Resource-Poor Settings: A Randomised Trial Comparing Counselling with Routine Medical Treatment in North Afghanistan (Mazar-E-Sharif)," BMC Psychiatry 12, no. 1 (2012): 14. 


\section{Livelihoods as a coping strategy against mental health risks}

For women, trainings are perceived to have a positive impact on their mental health, as they are opportunities for them to gather outside of their home. Trainings for women have dual impact: they not only teach them a skill that can potentially help them to become economically more independent, but also they have a positive impact on their mental health. The quantitative data show that $14.5 \%$ of the female respondents are currently enrolled in some form of short-term training, with $5.3 \%$ attending a tailoring course.

\section{No taboo - Strong willingness to seek treatment}

Of the 2,006 respondents 633 (31.6\%) indicated that they suffered from an illness or injury in a three-month period preceding the survey. Only $12.2 \%$ of these stated that they did not seek any help or treatment for their ailment. As Table 6 shows, the majority went to a private doctor $(30.6 \%)$, followed by clinics or mobile clinics (25.9\%) or a hospital $(25.7 \%)$.

Table 6: Help in case of sickness/injury

\begin{tabular}{lcc} 
& Frequency & Percentage \\
None & 77 & 12.2 \\
Private doctor & 194 & 30.6 \\
Clinic / mobile clinic & 164 & 25.9 \\
Hospital & 163 & 25.7 \\
Traditional birth attendant & 29 & 4.6 \\
\hline Traditional healer & 3 & 0.5 \\
Other & 3 & 0.5 \\
Total & 633 & 100
\end{tabular}

However, when disaggregating the data, socio-economic determinants appear to be crucial in the decisionmaking process. As shown in graph 5 below, illiterate people are for instance less likely to:

- Seek assistance or treatment from private doctors or hospitals, as they tend 'to be too expensive' (Focus Group Participant, Kabul, April 2014);

- Be aware of the existing opportunities, as 'their access to information and services is more limited' (KII with NNGO, Kabul, May 2014).

These distinctions apply using other vulnerability criteria: gender, migration history and income.

\section{Graph 6: Help in case of sickness/injury (by literacy level)}

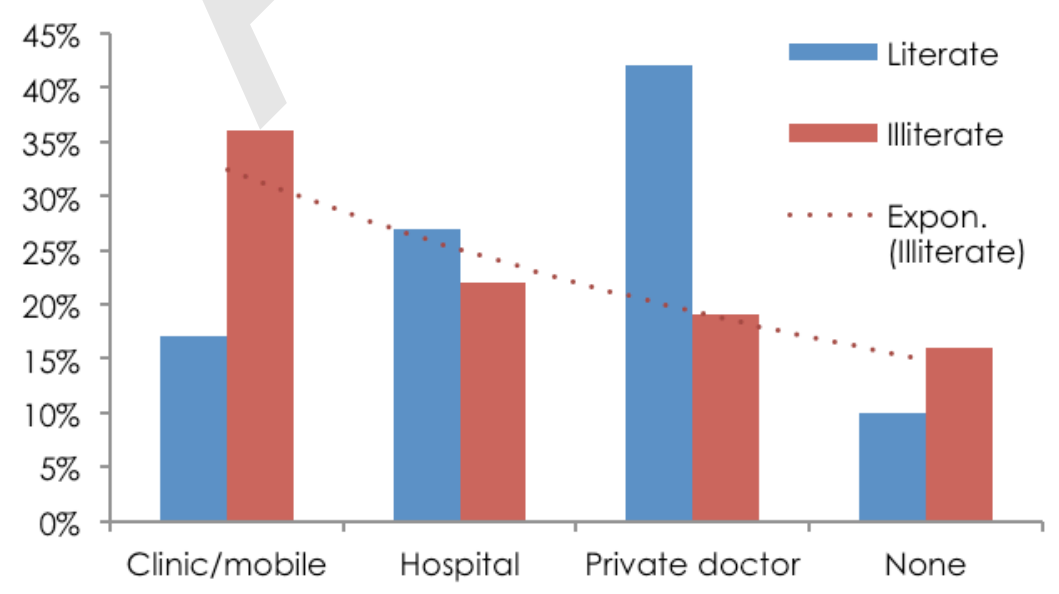

\section{Obstacles to health care for youth}

Discrimination on health care is a de facto reality for urban displaced youth in Kabul with concerning facts. Qualitative fieldwork showed that some people do not have access to health care due to an invisible urban barrier. This was particularly the case in IDP settlements, where clinics are lacking while needs are high. Even 
more, when community members of one IDP settlement visit other clinics, they complain about not getting sufficient attention because they are poor IDPs suggesting that IDPs feel discriminated against when accessing health facilities. This is also confirmed in the quantitative data. There we find that while $53.9 \%$ of IDPs indicate not having faced any sort of discrimination in accessing health care, this number is much higher for the other groups at between $63.7 \%$ for voluntary return migrants and $77.9 \%$ for rural-urban migrants.

Second, financial obstacles remain a key challenge in accessing health care. When asked what stood in the way of their access to health care, 59\% of the surveyed youth (and $75.6 \%$ for IDP youth) stated not having enough money to pay for a private doctor, clinic or hospital. Most of the health care in Kabul city is not free of charge, a fact that leads one quarter of respondents to identify discrimination by financial status.

Third, and a specific obstacle for women is the lack of family members to accompany them to seek treatment. Youth - whether due to their age, gender or lack of knowledge of their urban setting after displacement prefer not to go to seek treatment on their own. One in ten female youth lacks sufficient support within her surroundings to be able to access medical treatment.

Fourth, one in five respondents and half of surveyed women state that the lack of female health providers in the capital city remains an obstacle in their efforts to seek medical treatment.

Fifth and last, while this assessment did not specifically focus on jails and 'shelters', in-depth interviews with UNODC representatives and NGO representatives confirm the findings of past studies. They tend to aggravate pre-existing mental health conditions: 'the lack of assistance mechanisms has negative impacts, but this reality is amplified in a penitentiary environment'. 13

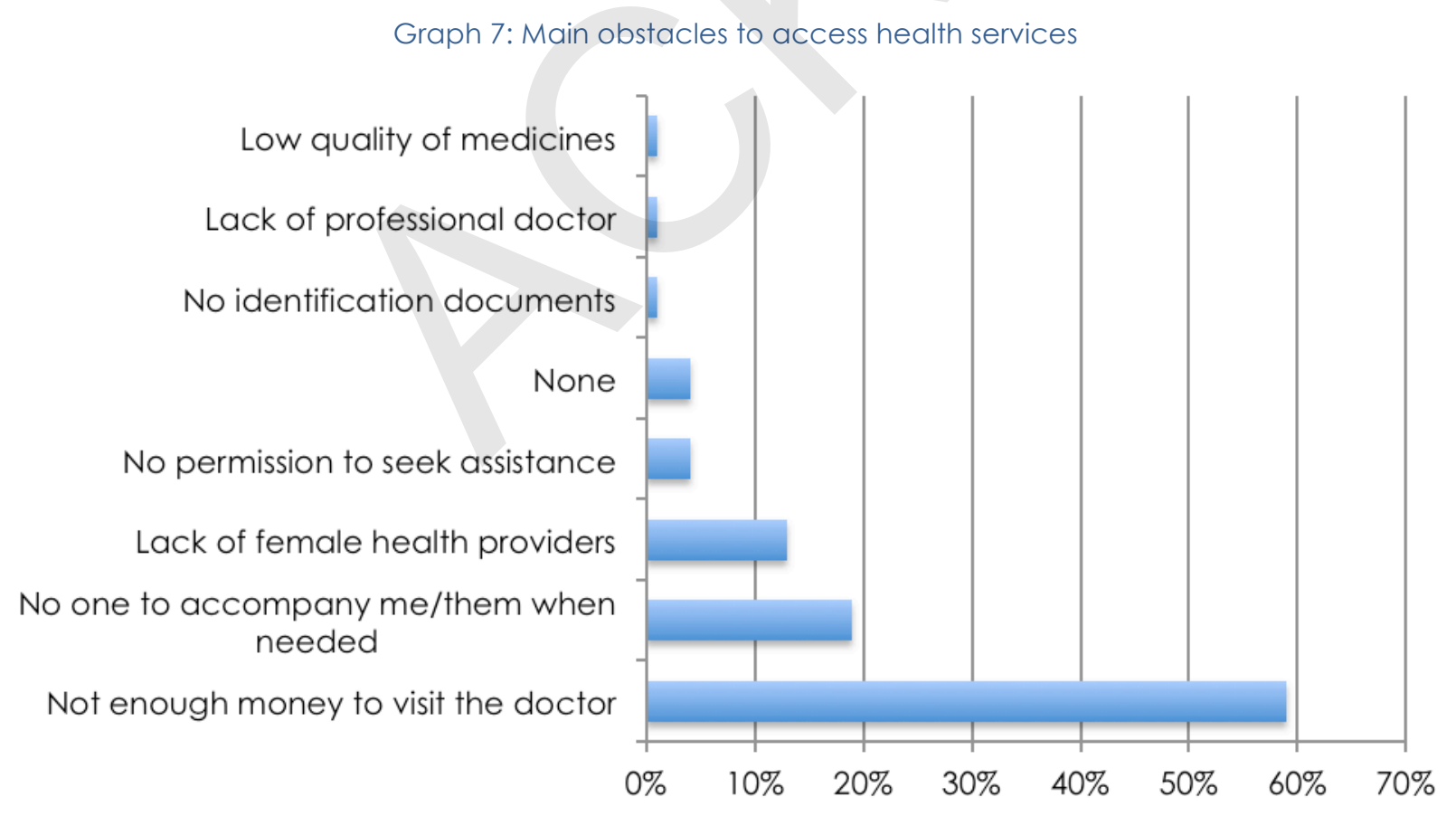

\footnotetext{
13 Key Informant Interview with UNODC, Kabul, January 2015. See also, for the situation of women in Afghan jails: 1) Human Rights Watch Afghanistan, I Had to Run Away - The Imprisonment of Women and Girls for 'Moral Crimes' in Afghanistan, March 2012; 2) World Bank I Samuel Hall, Gender and Justice Survey, January 2014.
} 


\section{Substance use}

Substance use is an area of growing concern for the health of young people in Afghanistan, the world's largest producer of opium and domestic drug addiction. UNODC's Afghanistan Drug Use Survey 2009 found around one million illicit drug users in Afghanistan (aged 15-64 years). ${ }^{14}$ This number represents around 3\% of the population, and significantly exceeds the world average. Iran and Afghanistan are reported to have the highest prevalence rates for opium and heroin use in the world. ${ }^{15}$ The 2009 survey found that opium is used by $60 \%$ of drug users and that the use of other drugs, like cannabis, has significantly increased during the last decade. Further, the survey found that opium and heroin are most commonly used by adolescents.16 The more recent Afghanistan National Urban Drug Use Survey (ANUDUS) 17 found that $11.4 \%$ of urban households had at least one person who tested positive for at least one substance (amphetamines, barbiturates, benzodiazepines, cannabinoids, alcohol or opioids). ${ }^{18} \mathrm{~A}$ panel debate on Youth and Mental Health on the occasion of International Youth Day 2014 also highlighted the misuse of easily available prescription drugs.

This study corroborates these findings and sheds light on key socio-economic vulnerability variables. While a relatively low number of respondents acknowledged using addictive substances (less than $25 \%$ of the total sample when including tobacco and naswar), it is worth noting that the $40 \%$ of the sample who reported being either 'illiterate' or 'poorly literate' tend to consume more addictive substances than the other group (of literate respondents): +4 percentage points for tobacco, +9 for naswar, +2 for cannabis.

More significantly, qualitative group discussions with Kabuli youth highlighted some of the usual root causes of drug consumption:

- Uncertainties about their future - 'I came to Kabul a year ago from Logar because of all the security problems we have there (...) I cannot find a job and sometimes I don't have enough money to eat. Today, I cannot survive without opium, it helps me forget' (Basir, 22 years);

- Anxiety - 'For us (girls), it is difficult to play a role in this society. My brothers do not even want me to go to University. So with my friends, we sometimes smoke to relieve pain and forget our fears' (Soheillah, 18 years);

- Recreational/social reasons - 'With my friends, we sometimes use drugs because you get bored easily in Kabul. I don't do serious drugs but sometimes we smoke shirak (= high-quality hashish) to enjoy ourselves and have fun' (Rashid, 17 years);

Once again, the literacy variable is relevant here, as it suggests that drug consumption also depends on access to education, information and awareness raising. However, similar results were obtained using other vulnerability criteria: gender, migration history and income. IDPs fare worse than other groups with significantly higher substance use rates of $24 \%$ for tobacco, $26 \%$ for naswar, $7 \%$ for cannabis and $4 \%$ for opium. As highlighted by UNODC: 'When it comes to drug addiction in today's Afghan context, it is difficult to distinguish any specific factor - be it education or income or displacement, etc. The root causes of addiction are a general nexus of multiple vulnerabilities. While migration, and especially displacement, was not necessarily a

\footnotetext{
14 UNODC, "Afghanistan Drug Use Survey 2009," 2009.

15 UNODC, "World Drug Report 2012" (Vienna, June 2012).

16 In the study adults are defined as people aged 26 or older, young people are defined as people between 16 and 25 years, adolescents are defined as people between age 10 and 15, and children as people below 10 years. - UNODC, "Afghanistan Drug Use Survey 2009." 2009.

17 The Afghanistan National Urban Drug Use Survey (ANUDUS) was conducted by the US Department of State with oversight by the MoPH. The survey studied 2,187 households and drug tested 5,236 people randomly selected from the general populations of 11 provincial capitals.

18 United States Department of State, "Afghanistan National Urban Drug Use Survey (ANUDUS)," December 2012.
} 
preeminent one, it has now become a major determinant as it reinforces other vulnerabilities - low income, social exclusion, etc.'19

Graph 8: Substance use (indicative figures by literacy level)

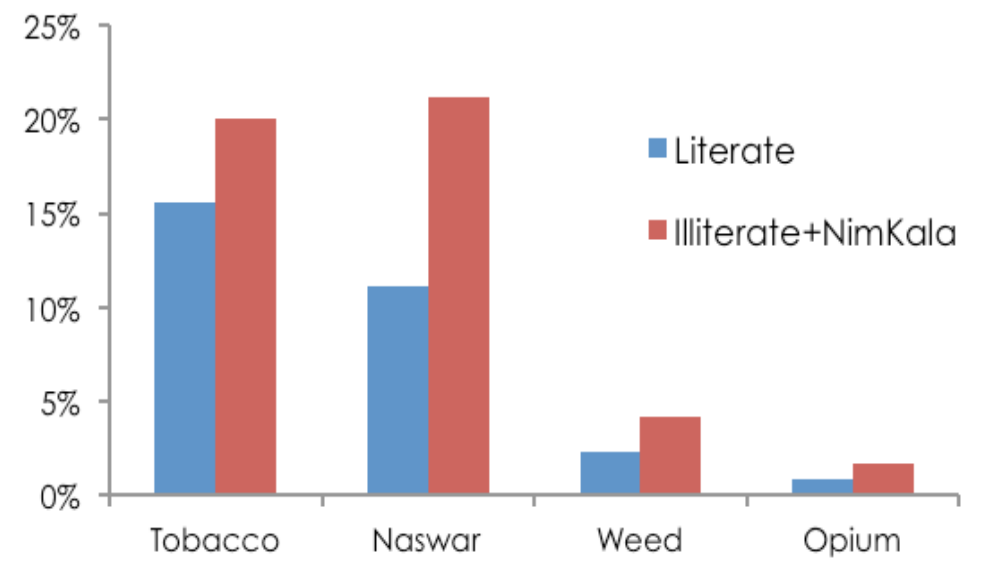

(nim kala = 'a bit' = very basic and non-marketable literacy level)

\section{UNEMPLOYMENT, BOREDOM AND OPIUM IN CHARAHI QANBAR}

When we first visited the neighbourhood of Charahi Qanbar, our initial meeting with the local community leaders was delayed, and finally cancelled, due to an emergency situation. We were supposed to discuss recent thefts and robberies that had affected the community and had apparently been committed by teenagers. However, the community leader had just found out that his son and his nephew had started using heroin, which caused a strong reaction from their families - and the community itself. 'There are a lot of young unemployed drug addicts. In this community there are approximately 70-80 youth addicts that have stopped coming home because they steal. In my opinion, this is a new trend, before they did not have this happening in their community' (Community leader, Charahi Qanbar, November 2014). Our follow-up visits and interviews confirmed a mix of concern about and resentment towards local youth. When asked to identify the causes of the new trend, most community members agreed on the diagnostic: 'Unemployment decreases the moral and motivation of youth. This affects their self-esteem, which in return leads to drug abuse' (Head of household, Charahi Qanbar, March 2015). Our interviews with local youth tend to validate this assumption, as well as the sharp increase in opium addiction in the neighbourhood. Some surveyed male youth seemed very distressed and complained about the discrimination they underwent on the job market and the boredom they suffered from in their community: 'There is no official place for youth to gather. We only pray in the mosque and it is too small to hold meetings' (Zabihullah, 22, Charahi Qanbar, April 2015). Some of them even confessed thinking about suicide out of desperation: 'What should we do? Should we kill ourselves, steal, kill others, block roads?' (Mohammed, 20, Charahi Qanbar, March 2015).

19 UNODC in Kabul, Key Informant interview, January 2015. 


\section{Conclusions: call for immediate and long-term action on youth (mental) health}

The major finding of this section is not only that Kabul's youth is voicing its suffering of mental health issues, but also that migration and displacement are relevant variables to understand and analyse the problem. As confirmed by focus group discussions with both youth and parents, as well as interviews with WHO respondents and NGO aid workers, traumatic disorders are likely to restrict youths' ability to engage, study, find a job and get fully integrated into the Afghan capital's socio-economic network. This also corroborates assumptions and conclusions of the WHO report on Mental Health and Development highlighting mental health as a major area for attention in development. 20 Psychosocial and psychiatric disorders are multifaceted issues, impacting social inclusion, interactions, employability and resulting in discrimination against a significant proportion of youth. Recommendations below cover a range of actions from national policy to local level measures.

Integrating policies to develop a national roadmap towards youth mental health in urban settings

Mental health should be a national cause in Afghanistan, and Kabul should be more than a pilot project. Under the umbrella and guidance of MOPH, DMOYA, WHO, donors, relevant international organisations, INGOs, NNGOs, and existing health facilities in the Afghan capital, a coordinated and long-term approach towards youth mental health should ensure that mental health services are both accessible and affordable. To this aim, the integration of a clear Mental Health Strategy into: i) the Urban Health Strategy, ii) the Child and Adolescent Health Strategy and iii) the Emergency, Preparedness and Response strategy would help address mental health issues experienced by youth, with a special focus on the most vulnerable categories (displaced youth).

\section{Promoting the multi-country return of qualified Afghans, with a specific focus on mental health professionals} While international donors have often privileged the return of qualified Afghan nationals as a way to facilitate the return of skilled Afghans from Pakistan, with a focus on education, economic development, and health, they have generally ignored the mental health sector - and especially youth mental health issues. IOM's RQAs (Return of Qualified Afghans) have generally proven successful in contributing to the rehabilitation of social services, and multiple lessons could be learned from almost 15 years of RQAs. However, considering the magnitude of the mental health issues, a more ambitious and systematic approach could be developed through professional exchanges, temporary returns, etc. - to address the massive lack of capacity in the mental health sector in Afghanistan and progressively build capacity in-country.

Creating and developing the skills of Afghan psychiatrists, psychologists and social aid workers, with a focus on the specific characteristics of youth mental health

Strengthen human resource development, especially the training of mental health professionals and psychosocial counsellors in community-based settings, and building the capacity of existing human resources should clearly be prioritised with a realistic action plan by all relevant stakeholders. The first WHO study conducted in 2004 points to a critical lack of trained psychiatrists, psychologists, mental health workers and nurses. Training skilled and semi-skilled mental health practitioners is clearly a key factor of any possible improvement of youth mental health and wellbeing. The lessons learned from IPSO (EU-funded project) and Afghanistan Libre could help design an intense training programme with potential on-the-job coaching and mentoring, which is definitely easier in Kabul than anywhere else in today's Afghanistan.

Strengthening the role of the Data for Development and Humanitarian Coordination Group

To progressively overcome the extreme lack of data vis-à-vis mental health in Afghanistan, the Data for Development and Humanitarian Coordination Group led by UNFPA, in coordination with relevant local authorities (CSO, MoPH), should initiate transversal assessments on: i) general data and information on the mental health situation of Afghan youth; and ii) specific assessments focusing on migrant/displaced urban

20 "Mental Health and Development: Targeting People with Mental Health Conditions as a Vulnerable Group" (Geneva, Switzerland: World Health Organization, 2010). 
youth. The technical expertise of key actors operating in urban settings and/or on migration/displacement such as UNHABITAT, UNHCR, IOM, NRC, DRC, Solidarités, WHH, etc. would be of great value to this initiative alongside mental health specialists to ensure that questions are asked in the right way, not creating more trauma, and adhering to the "do no harm" principle.

\section{Generalising awareness and information campaigns on mental health issues}

Changing the public and institutional perception of mental health conditions is essential to reducing stigma at a social and societal level. Training for practitioners and families, TV and radio campaigns, etc. could be used as awareness-raising instruments to overcome stigmatisation phenomena. This could also increase acceptance and knowledge of mental health disorders, including the negative consequences of substance abuse, GBV, violence against women and child marriage through a multi-sectorial approach, especially utilising religious leaders as message multipliers.

\section{Coordinating relevant urban and migration networks}

The mental health of urban migrant and displaced youth will clearly impact the social, economic and political future of the country. It is thus important to assess and promote it by coordinating the information, technical expertise and strategic priorities of WHO, UNHCR, UNFPA, IOM, IPSO, IMC, NRC, DRC, WHH, Solidarités, etc. in coordination with the Kabul Municipality, MOPH, MOUD, MORR, DMOYA.

- Establish and maintain a toll-free phone helpline to provide basic psychosocial counselling services to youth suffering from mental health issues. Trained counsellors should run the helpline.

- On the longer run, strengthen existing referral systems to improve referrals from the community level to mental health facilities (as detailed in the two recommendations below).

\section{Promoting community-based responses by involving all actors}

Any response needs to be as local as possible and even as local as the neighbourhood (nahia) level. To detect and address mental health issues of at-risk children and youth, who may warrant further healthcare interventions, it is crucial to establish community-based responses through: i) the support of relevant actors such as teacher counsellors at school and primary healthcare workers at the community level to assist in providing a rapid assessment of the child; and ii) on the longer run, appropriate referral systems (psychological counselling centres and mental health centres, with the caution suggested earlier) to refine the diagnostics and address immediate issues. This approach would not only increase the community's acceptance and role, it would also help: i) promote a life-course perspective to prevention and a more cost-effective medical approach; and ii) tailor the intervention to address a broad range of behavioural and mental health issues. In parallel, it is also important to strengthen the involvement of youth in community-level activities such as shuras, peer education systems and life skills programmes to mitigate the risk of social exclusion.

\section{Piloting mental health centres in urban settings}

To strengthen community-based responses and promote the availability and uptake of mental health services for the most vulnerable youth groups, pilot mobile units could be implemented in the main Kabul Informal Settlements and other places with high-density of returnees and IDPs. Those mobile units would detect and treat basic mental health issues, while playing a counselling and referral role towards youth suffering from more complex illnesses. This approach would have two main advantages: i) a pilot initiative would progressively overcome socio-cultural barriers and increase communities' and parents' acceptance of the 'invisible trauma'; and ii) this would reduce the barriers presented by one of the main obstacles (identified in focus groups) that migrant/displaced youth face in accessing health facilities, which are not only financial or sociocultural but also geographic, as returnee and IDP camps often have specific visible and invisible boundaries within Kabul. 


\section{Empowering the capacity of non-formal support systems}

Community mobilisation is a powerful tool in both rural and urban Afghanistan. As the vast majority of services for mental health conditions are provided outside the formal health sector (through family, community, local unskilled 'doctors', traditional and religious leaders), it is important to liaise with these actors in order to: i) provide a relevant entry point into mental healthcare and social inclusion and ii) build the capacity of informal actors while mitigating the risks of bad practices.

\section{Systematising early prevention projects}

The environment during a child's early stages of neurological and social development shapes the physical, social, cognitive and emotional foundation. In this regard, it is recommended to keep the big demographic picture in mind and 'start early' by reducing the burden of mental health conditions during early ages (childhood) rather than treating more complex problems later. ${ }^{21}$

\section{Tailoring assistance and programming to the most vulnerable}

In Kabul, promotion and prevention efforts should be tailored to specific migration and displacement profiles, as this study confirms that migration is an extremely valid variable to assess youth's traumas and mental disorders. Mental healthcare assistance in Kabul should prioritise tailored approaches to specific subgroups particularly vulnerable to (mental) health issues. Based on the findings of the study: i) IDP youth fare worse than all the other migrants - in symptoms of past trauma, substance use, etc. - and are clearly more likely to suffer from stress, anxiety or depression symptoms; ii) deportees often suffer from social-health issues (such as exclusion and stigma post-return) leading them to multiple psychiatric symptoms; and iii) women are much more frequently exposed to harassment, domestic violence, abuse, etc. than men.

\section{Improving detection and assistance mechanisms in penitentiary environments}

In coordination with UNODC, the Ministries of Interior (MOl) and Justice (MOJ), should strengthen their efforts to: i) promote alternatives to imprisonment for youth in pre-trial detention; ii) improve prison management; iii) introduce social reintegration programmes; and iv) create/generalize psychosocial detection/assistance mechanisms.

\section{Assessing results through triangulated M\&E approaches in Kabul}

Data should be collected regularly regarding a wide range of indicators across childhood into teenage years and emerging adulthood. Key vulnerability variables should systematically be assessed: gender, income, migration history, literacy level, etc. Supporting and sharing such consistent mental health knowledge databases would allow for efficient, contextualised and timely mental health programming for the urban youth. A working group co-chaired by WHO and the MoPH could make sure that data are used for surveillance, coordination and programming purposes.

\footnotetext{
${ }_{21}$ Center on the Developing Child, "The Foundations of Lifelong Health Are Built in Early Childhood" (Harvard University, July 2010).
} 


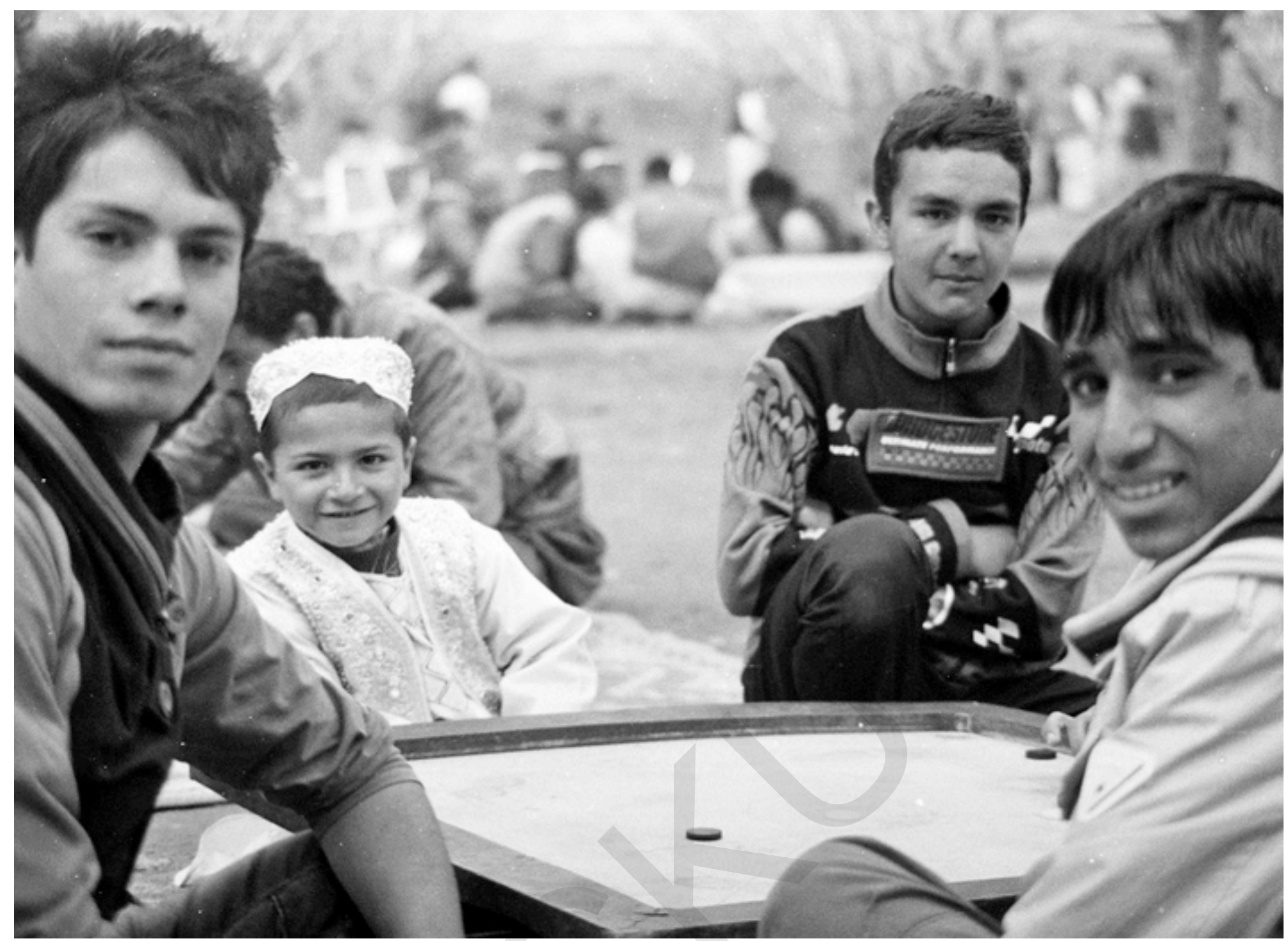

\section{CONTACTS}

info@samuelhall.org

development@samuelhall.org

www.samuelhall.org

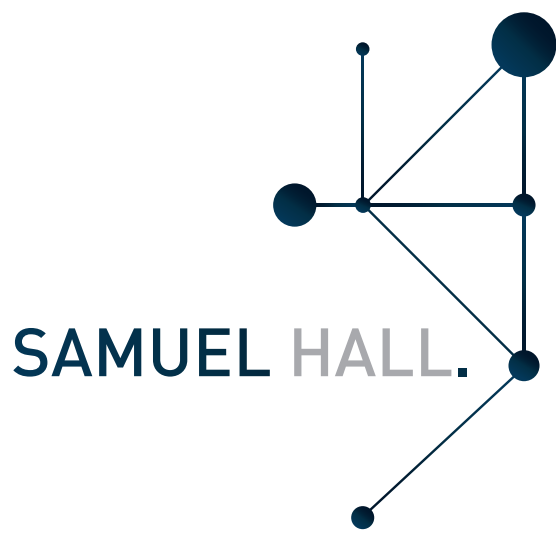

